\title{
Por uma Educação do Campo com as vozes da luta pela terra
}

Andréia dos Santos Pereira ${ }^{1}$, Hiran de Moura Possas ${ }^{2}$

\section{Resumo}

O artigo trata da importância de poéticas orais dos moradores do Projeto de Assentamento Grande Vitória, Marabá, Pará, como formação política no ensino de Língua Portuguesa e suas Literaturas, na Escola Família Agrícola Jean Hébette. As informações advêm de pesquisa realizada no curso de licenciatura em Educação do Campo, da Universidade Federal do Sul e Sudeste do Pará. Metodologicamente, foram consultados aportes teóricos interdisciplinares e realizadas entrevistas com agricultores do Projeto de Assentamento orientadas pela História Oral. As poéticas orais evocam temáticas dos modos de vida do campesinato: migração, resistência à violência no campo e conflitos entre projetos do capitalismo internacional $\mathrm{e}$ as populações tradicionais. Como resultados e encaminhamentos, compreende-se a necessidade de reafirmação dos atributos políticos do ensino do campo em diálogos críticos com historiografias linguísticas, literárias, canônicas e não canônicas.

\section{Palavras-chave}

Literatura. Poéticas orais. Educação do campo. Projeto de assentamento Grande Vitória.

\footnotetext{
${ }^{1}$ Graduada em Educação do Campo pela Universidade Federal do Sul e Sudeste do Pará, Brasil. E-mail: deinha123an@gmail.com.

${ }^{2}$ Doutor em Comunicação e Semiótica pela Pontifícia Universidade Católica de São Paulo, Brasil; professor adjunto da Universidade Federal do Sul e Sudeste do Pará, Brasil; líder do Grupo de Estudos Interculturais das Amazônias (GEIA/CNPQ/UNIFESSPA); integrante do grupo de pesquisa Comunicação e Cultura: Barroco e Mestiçagem (PUC/SP). E-mail: hiranpossas@gmail.com.
} 


\title{
For a Countryside Education with the voices of the struggle for the land
}

Andréia dos Santos Pereira ${ }^{3}$, Hiran de Moura Possas ${ }^{4}$

\begin{abstract}
The article deals with the importance of oral poetics of the residents of the Grande Vitória Settlement Project, Marabá, State of Pará, Brazil, as a political formation associated with the teaching of Portuguese language and its Literatures, at Escola Família Agrícola Jean Hébette. The information comes from research carried out in the degree course in Rural Education at the Federal University of the South and Southeast of Pará. Methodologically, interdisciplinary theoretical contributions were consulted and interviews were conducted with farmers from the Settlement Project with guidelines from Oral History. The oral poetics evoke themes that are significant to the peasantry's ways of life: migration, resistance to violence in the countryside and conflicts between projects of international capitalism and traditional populations. As results and directions, it is understood the need to reaffirm the political attributes of teaching in the field, in critical dialogues, with canonical, non-canonical, linguistic and literary historiographies.
\end{abstract}

\section{Keywords}

Literature. Oral poetics. Countryside education. Grande Vitória settlement project.

\footnotetext{
${ }^{3}$ Graduate in Contryside Education, Federal University of the South and Southeast of Pará, State of Pará, Brazil. E-mail: deinha123an@gmail.com.

${ }^{4} \mathrm{PhD}$ in Communication and Semiotics, Pontifical Catholic University of São Paulo, State of São Paulo, Brazil; adjunct professor at the Federal University of the South and Southeast of Pará, State of Pará, Brazil; leader of the Group for Intercultural Studies in the Amazon (GEIA/CNPQ/UNIFESSPA); member of the Communication and Culture research group: Baroque and Mestiçagem (PUC/SP).
} 


\title{
Introdução
}

\begin{abstract}
"Eu quero uma escola do campo que tenha a ver com a vida, com a gente, querida e conduzida coletivamente. Eu quero uma escola do campo onde o saber não seja limitado que a gente possa ver o todo e possa compreender os lados". (Gilvan Santos)
\end{abstract}

No artigo, pretende-se reafirmar a importância de narrativas orais sobre a luta pela terra dos moradores do Projeto de Assentamento Grande Vitória, em Marabá-PA, e suas possíveis e fundamentais inserções nos processos de ensino e aprendizagem da Escola Família Agrícola Jean Hébette.

A pesquisa ancorou-se em aportes teórico-metodológicos e ético-políticos relacionados às poéticas orais e à educação do campo, além daqueles tratando de pesquisas qualitativas para fenômenos sociais em contextos de povos do campesinato, a partir da perspectiva dos seus agentes, (res)significando suas vidas (GODOY, 1995).

Como princípio educativo, a pesquisa é a estrutura medular que dinamiza os tempos da Universidade e da Comunidade no Curso de Educação do Campo (UNIFESSPA, 2019). Na pesquisa em questão, professor e estudante elaboraram um roteiro simples, com destaque para o acesso à história de vida dos entrevistados e suas lembranças sobre a constituição do Projeto de Assentamento. As entrevistas seguiram pressupostos da história oral, cuja técnica de entrevista de história de vida e entrevista temática compreendem a fonte oral como "fonte viva, é uma fonte inacabada, que nunca será exaurida, e, portanto, que história bem-feita que queremos fazer é uma história inacabada” (VILANOVA, 1994). Exercício de escuta e diálogo: "uma entre-vista diz respeito a duas pessoas olhando uma para a outra. O observador nos observa - eles geralmente mais perspicazes do que nós, pois nos julgam a partir de nossa linguagem corporal e de comportamentos" (PORTELLI, 2016, p. 35).

Por questões éticas e políticas da região ${ }^{5}$, foram preservadas as identidades dos interlocutores. Concomitantes aos diálogos, procedimentos etnográficos foram decisivos e complementares às informações alcançadas pelos recursos audiovisuais. Escritos, reflexões e interpretações em diário de campo, com observação participante, compuseram o quadro reflexivo do escrito (PEIRANO, 1995).

$\mathrm{O}$ artigo apresenta quatro seções. A primeira descreve o histórico do curso da Educação do Campo, na Universidade Federal do Sul e Sudeste do Pará (UNIFESSPA),

\footnotetext{
${ }^{5}$ A região historicamente é marcada por práticas de violência fundiária contra lideranças camponesas.
} 
espaço acadêmico de realização da pesquisa. A segunda contextualiza o lócus da pesquisa: Projeto de Assentamento Grande Vitória e as narrativas de seus moradores. A terceira faz descrição da Escola Família Agrícola Jean Hébette. A quarta trata da memória da pesquisa “Acordes de cordéis testemunhos em poéticas do campesinato", destacando definições de poética oral e sua inserção no ensino de língua portuguesa e suas literaturas.

\title{
Por uma escola do campo com as vozes da luta pela terra
}

O sistema educacional brasileiro guarda dívida histórica com os povos da diáspora africana, dos indígenas, dos ribeirinhos e do campesinato brasileiro, dadas suas práticas de exclusão.

O curso de Licenciatura em Educação do Campo surgiu em 2009 na cidade de Marabá-PA, na então Universidade Federal do Pará (UFPA). Posteriormente, pela Lei no 12.824, de 5 de junho de 2013, a UFPA foi desmembrada, sendo criada a UNIFESSPA. O curso nasceu fruto de reivindicações históricas de movimentos sociais e das organizações populares atuantes na região em resposta aos graves problemas sociais existentes, nas regiões sul e sudeste do Pará.

\begin{abstract}
A criação de um curso de Licenciatura em Educação do Campo faz parte de uma ação mais ampla do Ministério da Educação (MEC), iniciada em 2003, para promoção da Política Nacional de Educação do Campo. Essa política vem sendo formulada pela atual Secretaria de Educação Continuada, Alfabetização, Diversidade e Inclusão (SECADI), através da Coordenação Geral de Educação do Campo (CGED) e do Grupo de Trabalho Permanente de Educação do Campo (GPT). (UNIFESSPA, 2019, p. 5).
\end{abstract}

Uma sucessão de eventos foi determinante para a existência do curso: a promulgação da Constituição de 1988; a criação da Lei de Diretrizes e Bases da Educação n. 9.394/96, em especial seu artigo 28, com o reconhecimento da diversidade e a singularidade do campo; realização do $1^{\circ}$ Encontro Nacional de Educadores e Educadoras da Reforma Agrária (ENERA), em 1997, organizado pelo MST e com apoio da Universidade de Brasília (UnB); criação e realização do Programa Nacional de Educação na Reforma Agrária (PRONERA), que foi uma política de Educação do Campo desenvolvida em áreas da Reforma Agrária entre os anos de 1998-2011 na região; criação da Secretaria de Educação Continuada, Alfabetização e Diversidade (SECAD), em 2004, atualizada para Secretaria de Educação Continuada, Alfabetização, Diversidade e Inclusão (SECADI), recentemente dissolvida pelo atual governo federal; e a realização de Editais PROCAMPO, O Programa de Apoio à Formação Superior 
em Licenciatura em Educação do Campo, na região, e a criação, em 2010, do Fórum Nacional de Educação do Campo (FONEC), uma articulação dos sujeitos sociais coletivos (Institutos de educação e universidades públicas, movimentos sociais e sindicais populares do campo e entidades que atuam na Educação do Campo) pelo princípio da autonomia do Estado brasileiro.

Das matrizes epistêmicas da educação do campo, podem ser destacadas, resumidamente, as formas de produção educativa do MST, Movimento dos Trabalhadores e Trabalhadoras Rurais sem Terra, fundamentadas na Pedagogia de Pistrak ${ }^{6}$. Segundo Freitas (2009), a Escola Comuna foi uma proposta de educação em bases socialistas, emanando para a escola questões, como: coletividade, auto-organização, e o trabalho como princípio educativo. E, sob o vértice do caráter emancipador da pedagogia freireana, é atributo da educação do campo o exercício de educação popular como projeto de classe interseccional, com o protagonismo de mulheres, indígenas, migrantes e meninos de rua (FREIRE, 2003).

O curso de Licenciatura em Educação do Campo da UNIFESSPA ancora sua dinâmica na Pedagogia da Alternância: diálogos de espaços, tempos, conhecimentos, práticas, vivências, sujeitos e experiências.

A partir das lógicas contraditórias, a alternância fará a interface entre a escola e o trabalho, com uma dupla função: "uma função econômica" com a finalidade da "inserção" e do "emprego", e "uma função pedagógica de qualificação", com a finalidade da "formação e qualificação". Daí a importância da Escola da Alternância que vai realizar "uma integração completa destas funções num sistema de interface entre a escola e o trabalho", com quatro dimensões importantes: institucional, pedagógica, didática e pessoal. (QUEIROZ, 2004, p.101)

O tempo-espaço universitário é constituído por aulas, seminários, rodas de conversas, sistematização e apresentação dos dados da pesquisa do tempo-espaço-local. No tempoespaço localidade, os discentes realizam, sob a orientação dos professores, pesquisas e diálogos com os conhecimentos, culturas, identidades e práticas pedagógicas de sua comunidade, valorizando a importância dos espaços educacionais ditos não formais. No entremeio desses tempos de atividades, eixos temáticos destacam problemáticas norteadoras para a realização de aulas, seminários e pesquisas: eixo 1: sociedade, estado, movimentos

\footnotetext{
${ }^{6}$ Moisey Mikhaylovich Pistrak (1888- 1937) foi educador russo do partido comunista da então URSS. Propunha, juntamente com um coletivo intelectual, a Escola Comuna: a superação da escola burguesa por uma escola revolucionária.
} 
sociais e questão agrária; eixo 2: educação do campo; eixo 3: saberes, culturas e identidades; eixo 4: sistemas familiares de produção; e o eixo 5: campo, territorialidade e sustentabilidade.

As áreas de conhecimento do curso, para a formação de educadores populares, são divididas em: Ciências Humanas e Sociais; Letras, Linguagens e Artes; Ciências Agrárias e da Natureza e Matemática.

o perfil profissional projetado para o curso inclui três conjuntos de aprendizagem básicos de formação para os educadores do campo: (1) Docência multidisciplinar em uma das áreas de conhecimento proposta pelo curso: Linguagens, Artes e Literatura; Ciências Humanas e Sociais; Ciências da Natureza e Matemática; Ciências Agrárias; (2) Gestão de processos educativos escolares, entendida como formação para a educação dos sujeitos das diferentes etapas e modalidades da Educação Básica, para a construção do projeto político-pedagógico e para a organização do trabalho escolar e pedagógico nas escolas do campo; (3) Atuação pedagógica nas comunidades rurais, o que significa uma preparação específica para o trabalho pedagógico com as famílias e ou grupos sociais de origem dos estudantes, para liderança de equipes e para a implementação (técnica e organizativa) de projetos de desenvolvimento comunitário sustentável. (CALDART, 2011, p. 3).

As áreas do conhecimento guardam disciplinas tratando temáticas comuns, sempre relacionadas às comunidades atendidas: a reforma agrária popular em região do latifúndio, grilagens de terra, soberania alimentar, saúde, agroecologia, conflitos decorrentes do Estado e os movimentos sociais, e a expansão dos projetos agropastoris e minerais.

Não é possível entender a covardia do latifúndio sem considerá-la na sua nervura exposta, que é especificamente a matança realizada através de emboscadas, na escuridão e sem a possibilidade de defesa, tanto da vítima imediata, como na certeza da impunidade, por isso a ausência do medo. (SILVA, 2020).

O curso, além de atender populações indígenas, ribeirinhas, quilombolas e camponesas do estado do Pará, também recebe estudantes de estados próximos, como o Maranhão. 
Figura 1 - Distribuição geográfica dos alunos da LPEC/FECAMPO/ UNIFESSPA

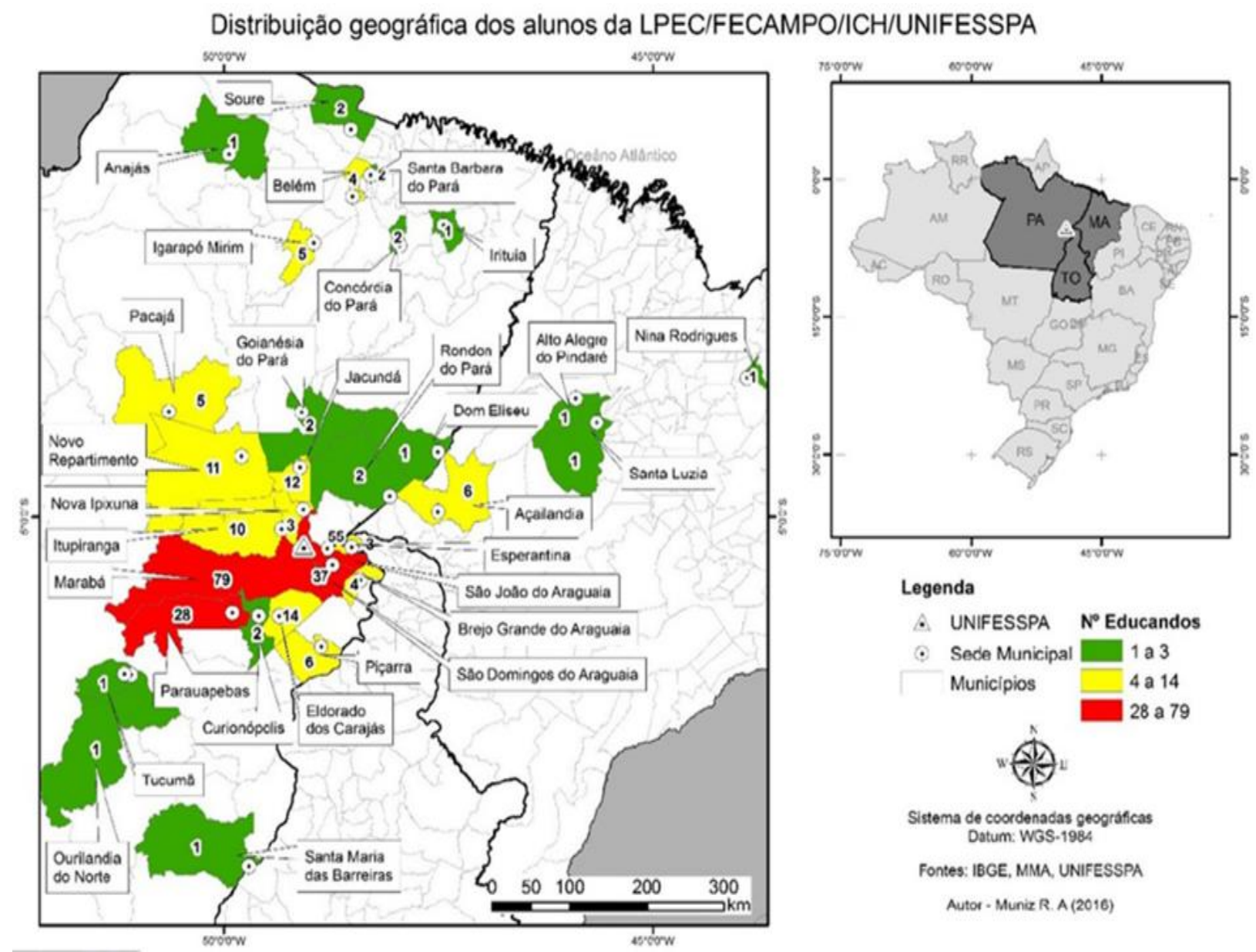

Fonte: MUNIZ, R. A. (2016).

O curso, anualmente, recebe cerca de 550 inscrições nos seus processos seletivos, ofertando, em média, 60 vagas. Apresenta um total de ingresso de 667 estudantes (121 alunos já formados $\left.{ }^{7}\right)$. Atualmente, o corpo docente é composto por 23 profissionais efetivos e 1 substituto, originários de diferentes áreas do conhecimento (Agronomia, Geografia, História, Antropologia, Biologia, Pedagogia, Letras, Matemática, dentre outras) ${ }^{8}$.

\section{Projeto de assentamento Grande Vitória}

O Assentamento Grande Vitória fica localizado às margens da Rodovia Transamazônica, km 21. Ocorreu a ocupação, no ano de 1999, com 98 famílias compostas de

\footnotetext{
7 As informações correspondem ao período de 2010-2017. Disponível em: https://sigaa.unifesspa.edu.br/sigaa/ensino/discente/busca.jsf.

${ }^{8}$ Disponível em: https://fecampo.unifesspa.edu.br/corpo-docente.html
} 
agricultoras e agricultores, vivendo às margens do rio Tocantins, nas proximidades do município de Marabá-PA. O processo foi marcado por três ordens judiciais de desapropriação, ameaças e práticas violentas do suposto proprietário?.

Reminiscências de agricultores relatam ameaças aos acampados e a ocorrências de mortes e a presença de corpos enterrados em cemitérios clandestinos, na antiga fazenda. Certas narrativas demonstram esquecimentos forçados, traumáticos e estratégicos daqueles que viveram os horrores da pistolagem e as desconfianças da segurança pública.

O Projeto de Assentamento Grande Vitória, atualmente, é constituído por 106 lotes. Há prevalência da agricultura familiar e a criação de gado. A área do Assentamento é de 1737.0810 Ha (hectares), com lotes divididos por tamanhos variados em duas áreas: o lado alto possui 58 lotes, a maior parte coberta de pastagem para a criação bovina; o "Baixão" é composto por 48 lotes, com uma área de mata ciliar às proximidades do rio Tocantins. Os loteamentos têm, em média, de 5 a 7 alqueires ${ }^{10}$.

No Assentamento, há duas escolas: a Escola Municipal de Ensino Fundamental Santa Maria, que atende alunos da comunidade; e a Escola Família Agrícola Jean Hébette , recebendo estudantes do Assentamento e de outras cidades e comunidades rurais.

\section{A Escola Família Agrícola Jean Hébette}

As Escolas Famílias Agrícolas (EFAS) preconizam a valorização de experiências cotidianas dos estudantes e suas famílias nos espaços considerados rurais. Objetivam formular ações pedagógicas concomitantes ao desenvolvimento socioambiental das comunidades do campo. As matrizes de sua proposta chegaram ao Brasil por padres italianos, na década de 70.

A escola Família Agrícola Jean Hébette ${ }^{11}$ localiza-se no Projeto de Assentamento Grande Vitória, município de Marabá/Pará. Trata-se de uma propriedade privada (espaço alugado e mantido pela Prefeitura Municipal de Marabá-PA), de estrutura física modesta, com duas salas de aulas. A escola tem uma área de 25 hectares, contendo 4 açudes ( 3 utilizados para piscicultura e o outro como nascente). Há também uma pocilga, um aviário, um viveiro,

\footnotetext{
${ }^{9}$ Assim como grande número de latifundiários da região, o "proprietário" foi acusado da prática de invasão de áreas públicas e da fraude de documentos. No passado, insetos eram inseridos em uma caixa com as documentações; com o tempo, os papéis ganhavam aspecto de envelhecimento.

10 As informações do Projetos de Assentamentos da região são públicas e disponíveis em: https://www.gov.br/incra/pt-br/assuntos/reforma-agraria/assentamentosgeral.pdf/view.

11 Religioso belga com atuação acadêmica significativa na Amazônia. Seu legado intelectual e militante de movimentos sociais deixou fortes marcas nos estudos de desenvolvimento regional e da teoria do campesinato, assim como contribui para o fortalecimento de ações de sindicatos rurais e da Comissão Pastoral da Terra no trato das questões fundiárias.
} 
um campo de futebol e uma praça ecológica. Existem 2 alojamentos (masculino/feminino), 1 auditório e 1 refeitório (utilizados como sala de aula), cozinha e 10 banheiros (distribuídos pelo espaço). A EFA ${ }^{12}$ é constituída por 4 turmas do ensino fundamental, com a dinâmica da pedagogia da alternância (DA SILVA LOBO, 2018, p. 36).

\begin{abstract}
A EFA da região de Marabá possui dois momentos da atividade. No primeiro a escola teve sua origem a partir da ideia de criar uma escola agrícola para jovens que ainda estavam no início da caminhada. Essa ideia resultou no evento denominado I Encontro de Jovens Camponeses, realizado em outubro de 1993, pela Fundação Agrária do Tocantins Araguaia (FATA) no âmbito do Programa Centro Agroambiental do Tocantins (CAT), em conjunto com seus Sindicatos dos Trabalhadores rurais (STR) de Marabá, Itupiranga, Jacundá, São João do Araguaia, São Domingos e Nova Ipixuna.
\end{abstract}

Historicamente, o Brasil, no seu processo de industrialização, fez da escola uma extensão de princípios tecnicistas, resposta a uma lógica de formação ao mercado de trabalho, com a difusão do conhecimento escolar estruturado para atender às necessidades dessa mercantilização. Observa-se que, em certa medida, a Escola Família Agrícola Jean Hébette vem rasurando as suas matrizes propositivas, intencionalmente ou não ${ }^{13}$, com a formação de "recursos" humanos com perfis mais próximos dos requisitos das corporações.

É recorrente certos distanciamentos discursivos dos movimentos sociais. Não é mais incomum, nos segmentos da escola, falas criminalizando as ocupações dos latifúndios (primeira das inúmeras ações da reforma agrária popular). Há, por nossa perspectiva, uma "crise" de memória.

\title{
Poéticas orais: repensando o cânone
}

O projeto "Acordes de cordéis testemunhos em poéticas do campesinato", realizado junto à Faculdade de Educação do Campo da UNIFESSPA, desde 2014, faz escutas de contextos do campesinato. A experiência dos autores, com a Pedagogia da Alternância permitiu uma maior e melhor aproximação com as chamadas comunidades rurais.

A Pedagogia da Alternância permite aos jovens do campo a possibilidade de continuar os estudos e de ter acesso aos conhecimentos científicos e tecnológicos não como algo dado por outrem, mas como conhecimentos conquistados e construídos a partir da problematização de sua realidade, que

\footnotetext{
12 Abreviatura de Escola Família Agrícola.

${ }^{13}$ Relativiza-se a questão por merecer continuidade de pesquisas de campo e, consequentemente, a melhor audição dos demais atores desse processo.
} 
passa pela pesquisa, pelo olhar distanciado do pesquisador sobre o seu cotidiano. (CORDEIRO; REIS; HAGE, 2011, p. 115-116).

Foram realizadas entrevistas com agricultores do Projeto de Assentamento Grande Vitória e, desses diálogos, temas caros, propositalmente omitidos pelas engrenagens capitalistas da legalização das ilegalidades, mereciam, com os devidos cuidados à segurança dos narradores, divulgação. No processo de escuta, as narrativas não se limitavam ao dito, mas guardavam formas "estranhas" do dizível: o corpo e seus suores; os toques nos ouvintes e a gradação da voz às emoções demonstravam que o reino da poesia não se restringe às letras, às linhas ou aos ditames do mundo grafocêntrico.

A historiografia literária ${ }^{14}$ é excludente. A Poesia oral, quando reconhecida, é Paraliteratura $^{15}$. Marginalização, em sentidos depreciativos, imposta por "Literatura" eurocêntrica e canônica. As poéticas orais extrapolam o mero entendimento do signo por representações gráficas. Residem nelas "outros letramentos", códigos simbólicos e epistêmicos carregados de racionalidades e alteridades cognitivas contra hegemônicas.

O trabalho com as poéticas tem sido uma investida que subverte a lógica dos estudos literários, trata-se, antes de tudo, de uma aventura contra o cânone. Um lance audaz na tentativa de reformular as estruturas dominantes da crítica literária. No entrelugar da cultura e dos estudos literários nos embrenhamos e tiramos do limbo as culturas das bordas. O que faz pensar que temos o direito de excluir as formas narrativas orais dentro dos estudos literários? (PIMENTEL; AKEL, 2014, p. 196).

O questionamento encoraja a luta pela democratização poética e pela crítica às estruturas canônicas, confinando as poéticas orais ao primevo, ao folclórico e ao popular, em seus sentidos mais redutores. Lutar contra o cânone é lutar por uma diversidade da poesia e da literatura, ou como dizem os intelectuais, da diáspora africana: a luta pelo reconhecimento e valor da oratura ou literatura oral.

A literatura oral, expressão criada por Sébillot (1983), é uma resposta à miopia literária e cultural que tentou camuflá-la ou reduzi-la ao folclore ou ao popular. Poesia oral é outra coisa, tem uma acepção mais larga nas perspectivas sociológicas, antropológicas e literárias, pois tão fortemente social quanto individual, a voz mostra de que forma o homem se situa no mundo em relação ao outro, como é capaz, seja através de mito, poéticas narradas ou através de cordéis, de atualizar os paradigmas literários, apresentando uma convencionalidade particular, híbrida e permeável, revelada numa poética comparável à secreção do corpo humano. A função

\footnotetext{
${ }^{14}$ Marco temporal de orientação ocidental para textos considerados literários.

${ }^{15}$ Textos considerados não canônicos, menores e de pouca erudição.
} 
dessa arte não é nada modesta: não é comparativa, e sua primariedade deve ser entendida como primeira, vivendo, mergulhando e norteando sua vida nas repetições cíclicas, reatualizadas, dos fenômenos (POSSAS, 2010, p. 146).

A voz dos artistas narradores são realidades vividas. Os vários "eus" do narrador, do escritor e dos personagens são efeitos dos espaços e tempos. Nesse viés, as poéticas orais não podem ser definidas, avaliadas e mensuradas por parâmetros do mundo da escrita. Elas desafiam as pesquisas a aprender com categorias analíticas surgidas a partir das performances do corpo e da voz.

\section{Vozes da exclusão, da migração e da violência no campo}

O trabalho com as poéticas orais campesinas significa que há grandes latifúndios do cânone literário. Estamos lutando contra arames farpados do sistema literário, delimitando espaços marginais ou não espaços. Os sujeitos subalternos e suas poéticas sofreram rasuras, construção de um ethos, de pensamento reificado, para a diversidade brasileira. Pensar em trabalhar com essas poéticas, no contexto escolar, é construir contra dispositivos discursivos ${ }^{16}$ à literatura branca, criminosa, excludente e preconceituosa.

Historicamente, a escola celebra a literatura ocidental, destacando o protagonismo do narrador colonizador e a sua versão do contato com os povos nativos: imperialista e marcada pelo ordenamento do que seria cultural e não cultural.

Verifica-se, contudo, alguns - tímidos - avanços no que se refere, especificamente, ao ensino de literatura, defendendo-se a necessidade de a escola trabalhar com as literaturas "marginalizadas e de periferia", de autoria africana, afro-brasileira, indígena e latina. (AMORIM; SILVA, 2019, p. $155)$.

As verdades de sujeitos subalternizados, por ações libertadoras da escola, devem ganhar força e visibilidade para que experiências pedagógicas mais democráticas sejam reproduzidas.

\footnotetext{
${ }^{16}$ Foucault e Deleuze, e um número significativo de estudiosos, trataram a categoria analítica para análises de políticas de subjetivação. Ancoramos a nossa compreensão às de Giorgio Agamben (2009) quando, na definição de dispositivo como qualquer coisa que tenha a capacidade de capturar, orientar, determinar, interceptar, modelar, controlar e assegurar os gestos, as condutas, as opiniões e os discursos dos seres viventes, por prisões, manicômios, panópticos, escolas, fábricas, disciplinas e as medidas jurídicas, propõe, como política de dessubjetivação, o exercício de pontos de fugas no interior de seus mecanismos reguladores da liberdade.
} 
mas atualmente eu sô agricultor, a vinte ano, vinte ano, vinte dois anos, vinte cinco anos por aí, eu acho por aí sô agricultor, a minha família toda é camponesa sou fie de camponês nasci e me criei no campo passei uns tempos trabalhando como operário mais agora no final das décadas eu continuo agricultor entende? (NARRADOR 3, 2019).

O testemunho do agricultor relata sua saída forçada do campo em busca de outras formas de trabalho, sem, contudo, significar interferência na sua auto identificação como agricultor. As experiências, como operário e serviçal no sistema industrial capitalista, reforçaram seu desejo de regresso e valorização do trabalho no campo.

já passei umas fases muito difícil na minha vida assim (silêncio) porque quando o cara é (choro), eu hoje tô passando pus 68 anos, hoje, esse ano, então assim ó, a gente começou vivendo, cum pai pobre mãe pobre quebradeira de coco lá no maranhão, minha mãe quebrava coco no dia a dia de casa pra ajudar meu pai na agricultura, isso a gente traz assim dentro da gente, aquela coisa que não acaba, entendeu? (NARRADOR 3, 2019).

O enunciado destaca o lugar de "desimportância" reservado às quebradeiras de coco e babaçu. Mulheres camponesas, pela "racionalidade" do capital, são naturalizadas à força secundária e complementar de renda e do trabalho.

O tema da migração é outra questão relevante das narrativas acessadas:

É assim eu, eu sou piauiense, eu vim pro Pará largado da mulher [...] deixei uma roça completa de algodão, fava e milho que foi no mês de setembro né? [...] fui pra Serra Pelada, aí foi lá na serra pelada foi que me tratei dessa malária, aí depois que sairei dessa malária aí passei a trabalhar em fazenda tomando conta da fazenda tá entendendo? (NARRADOR 4, 2019)

O narrador demonstra suas compreensões à temática da migração: 1) A busca de melhores condições de vida; 2) O desamparo forçado da família; 3) O trabalho, em condições escravas, no garimpo de Serra Pelada. A Migração, portanto, é questão sine qua non para o ensino e a compreensão da constituição territorial na Amazônia.

As experiências do narrador, com a Escola Itinerante do Movimento dos Trabalhadores e Trabalhadoras Rurais Sem Terra - MST, demonstram o processo de partilha de conhecimentos e a compreensão de como os setores da luta pela terra são organizados: alimentação, trabalho da limpeza e saúde, dentre outros.

até quando os meninos entraram na série, aí teve uma um colegiozinho bem ali onde é a Kauam. A Elizabeth, que era a presidente. se reuniu, fizemos um 
barracãozinho lá de palha, aí fizemos um colegiozinho lá, aí meus meninos já vieram estudar aqui. (NARRADOR 1,2016).

Eu tenho 17 anos que convivo aqui dentro desse P.A. E eu acho que se tivesse uma possibilidade de uma escola com ensino médio aqui dentro seria muito bom, até porque evitava alguns tumultos de aluno, né, indo pra outra escola saindo pra se misturar com os de lá. (NARRADOR 2, 2019).

O testemunho do agricultor destaca a formação, a reflexão e a deliberação para crianças e adultos no processo de ocupação de terras. Também descreve certa ruptura com a rotina comunitária quando parece optar pelas vivências, às escolas urbanas: preconceito por ser do campo e o desconforto com práticas pedagógicas distantes do universo pedagógico antes experienciado.

A construção de escolas nas comunidades camponesas e o prosseguimento da formação militante são negligenciados pelo Estado brasileiro. Esse bloqueio eugênico de humanidades, suas poéticas e práticas letradas do corpo.

\section{Considerações finais}

Para pensarmos um trabalho pedagógico que dê foco às narrativas orais, precisamos abrir espaços para as alteridades de contextos subjugados e menosprezados: dar passagem à riqueza estética das vozes da diversidade. O campo, não nos esqueçamos, já é um território educativo, epistêmico, metodológico e de múltiplas subjetividades.

Precisamos ser atuantes na crítica dos espaços de negação da organicidade do campesinato. Dentre tantas, a retirada estratégica do Estado na resolução das problemáticas agrárias, na Amazônia.

Pesquisar e aprender com a cotidianidade do campesinato e torná-la mais reluzente aos debates acadêmicos, fortalece nossa militância pelo respeito e cumprimento de cláusulas pétreas constitucionais, direitos individuais e coletivos negados ou descumpridos, historicamente, dos povos do campesinato.

Um processo de reeducação estética não se desaparta da reeducação política. A escola historicamente serve como dispositivo de aniquilação ontológica. Narcisicamente, o projeto moderno se instaura na escola eurocêntrica, patriarcal e defensora da propriedade privada. Isso não foi suficiente, porém, para que outras agências cósmicas abdicassem de refletir e fazer os exercícios de suas experiências (in)formais de ensino.

Há tempo para a revisão dessa equação civilizatória oportunista, situacional e persistente que se impõe, por jogo agonizante das falsas e cruéis diferenças: o capitalismo 
internacional. A escola deve ser a nossa pharmakon, remédio, na medida radical de conceder "língua" às sabedorias locais, plasmando discursos para o fracasso e da falência da (ir)racionalidade empreendedorista, contábil e individualista.

\section{Referências}

AGAMBEN, G. O que é dispositivo. In: AGAMBEN, G. O que é o contemporâneo e outros ensaios. Chapecó: Argos, 2009. p. 27-51.

AMORIM, M. A. de; SILVA, T. C. da. O ensino de literaturas na BNCC: discursos (re)existências possíveis. In: GERHARDT, A. F.; AMORIM, M. A. de (org.). A BNCC e o ensino de línguas e literaturas. Campinas: Pontes Editores, 2019. p. 153-179.

CALDART, R. S. Licenciaturas em Educação do Campo: registros e reflexões a partir das experiências piloto (UFMG; UnB; UFBA e UFS). Belo Horizonte: Autêntica, 2011.

CORDEIRO, N. K G.; REIS, N. da S.; HAGE, S. M. Pedagogia da Alternância e seus desafios para assegurar a formação humana dos sujeitos e a sustentabilidade do campo. Em aberto, Brasília, v. 24, n. 85, p. 115-125, abr. 2011. Disponível em:

http://rbep.inep.gov.br/ojs3/index.php/emaberto/article/view/3078. Acesso em: 20 maio 2021.

DA SILVA LOBO, D. Agroecologia e educação do campo: experiências educativas da Escola Família Agrícola (EFA), no município de Marabá. Dissertação (Mestrado em Dinâmicas Territoriais e Sociedade na Amazônia) - Universidade Federal do Sul e Sudeste do Pará, Marabá, 2018.

FREIRE, P. Educação e participação comunitária. In: FREIRE, P. Política e educação. 7. ed. São Paulo: Cortez, 2003.

FREITAS, L. C. de. A luta por uma pedagogia do meio: revisitando o conceito. In: PISTRAK, M. (org.). A escola-comuna. São Paulo: Expressão Popular, 2009.

GLISSANT, E. Introdução a uma poética da diversidade. Tradução de Enilce do Carmo Albergaria Rocha. Juiz de Fora: EDUFJF, 2005.

GODOY, A. S. Pesquisa qualitativa tipos fundamentais. Revista de Administração de Empresas, São Paulo, v. 35, n. 3, 1995. Doi: 10.1590/S0034-75901995000300004.

Disponível em: https://www.scielo.br/j/rae/a/ZX4cTGrqYfVhr7LvVyDBgdb/?lang=pt. Acesso em: 10 abr. 2021.

NARRADOR 1. Entrevista oral [gravada] realizada por Andreia dos Santos Pereira. Marabá, Pará, 15 de outubro. 2016. 1 h05 min.

NARRADOR 2. Entrevista oral [gravada] realizada por Andreia dos Santos Pereira. Marabá, Pará, 28 de abril. 2019. 1h24 min. 
NARRADOR 3. Entrevista oral [gravada] realizada por Andreia dos Santos Pereira. Marabá, Pará, 9 de março. 2019. 1h30min.

NARRADOR 4. Entrevista oral [gravada] realizada por Andreia dos Santos Pereira. Marabá, Pará, 26 de maio. 2019. 1h32 min.

PEIRANO, M. A favor da etnografia. Rio de Janeiro: Relume-Dumará, 1995.

PIMENTEL, D.; AKEL, J. F. O lugar das poéticas orais. Boitatá, Londrina, v. 9, n. 17, p. 191-212, jan.-jul. 2014. Disponível em:

https://www.uel.br/revistas/uel/index.php/boitata/article/view/31661. Acesso em: 20 maio 2021.

PORTELLI, A. História oral como arte da escuta. Tradução de Ricardo Santhiago. São Paulo: Letra e Voz, 2016.

POSSAS, H. de M. Poéticas orais: sopros das tradições na contemporaneidade. Mato Grosso do Sul: EDUFGD, 2010.

QUEIROZ, J. B. P. de. Construção das Escolas Famílias Agrícolas no Brasil: ensino médio e educação profissional. Tese (Doutorado em Sociologia) - Universidade de Brasília, Brasília, 2004.

SANTOS, G. Cantares da Educação do Campo. 2006. Disponível em: https://mst.org.br/download/mst-cantares-da-educacao-do-campo-caderno-de-letras-e-cifrasde-musicas/. Acesso em 15 maio 2021.

SILVA, J. As curvas da barbárie: a atualidade do massacre de Eldorado dos Carajás. Marabá, terra bendita [blog], abr. 2020. Disponível em: https://marabaterrabendita.blogspot.com/search?q=as+curvas. Acesso em: 20 maio 2021.

VILANOVA, M. Pensar a subjetividade-estatísticas e fontes orais. In: MORAES, M. (org). História oral. Rio de Janeiro: Diadorim, 1994.

Submetido em 28 de junho de 2021.

Aprovado em $1^{\circ}$ de outubro de 2021. 